\title{
Plasma membrane ion channels and epithelial to mesenchymal transition in cancer cells
}

Iman Azimi1,2,3 and Gregory R Monteith1,2,3

1The School of Pharmacy, The University of Queensland, Brisbane, Queensland, Australia 2Mater Research Institute, The University of Queensland, Brisbane, Queensland, Australia

${ }^{3}$ Translational Research Institute, Brisbane, Queensland, Australia
Correspondence should be addressed to G R Monteith

Email

gregm@uq.edu.au

\begin{abstract}
A variety of studies have suggested that epithelial to mesenchymal transition (EMT) may be important in the progression of cancer in patients through metastasis and/or therapeutic resistance. A number of pathways have been investigated in EMT in cancer cells. Recently, changes in plasma membrane ion channel expression as a consequence of EMT have been reported. Other studies have identified specific ion channels able to regulate aspects of EMT induction. The utility of plasma membrane ion channels as targets for pharmacological modulation make them attractive for therapeutic approaches to target EMT. In this review, we provide an overview of some of the key plasma membrane ion channel types and highlight some of the studies that are beginning to define changes in plasma membrane ion channels as a consequence of EMT and also their possible roles in EMT induction.
\end{abstract}

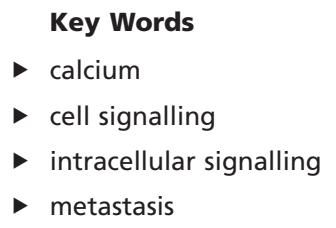

Endocrine-Related Cancer (2016) 23, R517-R525

\section{Introduction}

Epithelial to mesenchymal transition (EMT) refers to the process whereby epithelial cells which typically exhibit features such as strong cell to cell adhesion and apicalbasal polarity, lose these properties and acquire others such as greater motility and a spindle like morphology (Thiery et al. 2009, van Denderen \& Thompson 2013) (Fig. 1). EMT is a key event in developmental processes including embryogenesis where it is associated with implantation and embryonic gastrulation (Kalluri \& Weinberg 2009). EMT is also a feature of other aspects of normal physiology such as wound healing where it has an important role in tissue regeneration, and organ fibrosis (Kalluri \& Weinberg 2009).

\section{EMT in cancer}

Metastasis is the cause of mortality in cancer types that originate from organs where surgical resection and/or treatment of the primary tumour are often feasible (e.g. breast and prostate). Metastasis is a highly regulated process whereby cells escape the primary tumour, enter the circulatory system and deposit at a metastatic site (Hanahan \& Weinberg 2011). There is clear coordination of processes in metastasis and this is reflected in the propensity of different cancer subtypes to preferentially form metastatic lesions in specific sites. The loss of cellto-cell adhesion, the acquisition of motility, the ability to degrade the surrounding extracellular matrix and to survive stresses such as that induced by entry into the circulation are all features that are required of cancer cells during metastasis. It is therefore not surprising that it is believed that as cells leave the primary tumour they may undergo processes similar to EMT (Heerboth et al. 2015). These include the expression of the specific transcription factors Snail and Twist, expression of mesenchymal

Published by Bioscientifica Ltd 


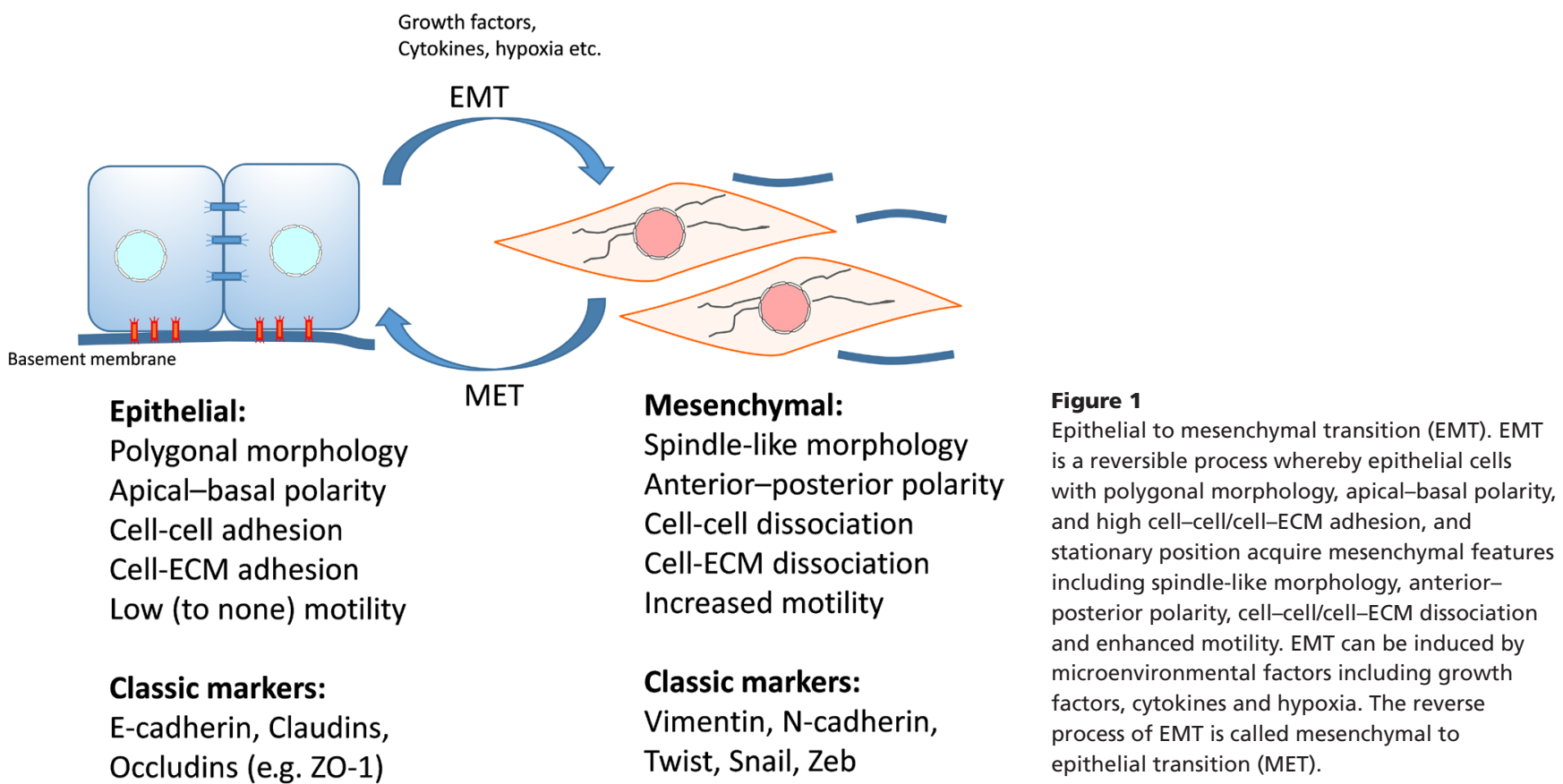

markers such as vimentin and N-cadherin, and loss of epithelial markers such as E-cadherin (Tsai \& Yang 2013). Indeed, the consequences of EMT have been reported as increased motility and a remodelling of cellular adhesion (Lamouille et al. 2014). EMT in cancer cells is also associated with the acquisition of therapeutic resistance (Singh \& Settleman 2010). Although some very recent studies indicate that in some cancers EMT may be more important in the acquisition of therapeutic resistance than metastasis (Fischer et al. 2015, Zheng et al. 2015), understanding the induction of EMT and the properties of the mesenchymal state would clearly help identify novel therapeutic targets.

A number of factors in the tumour microenvironment have been identified as inducers of EMT in cancer cells. In breast cancer cells, growth factors such as epidermal growth factor (EGF), and hypoxia have been shown to induce EMT in a variety of in vitro models, such as MDA-MB-468 breast cancer cells and ZR-75-1 breast cancer cells (Lester et al. 2007, Davis et al. 2014a). In prostate cancer cells, EMT is induced by epidermal growth factor (EGF) (Zhang et al. 2013b) and Growth and differentiation factor 9 (GDF-9) (Bokobza et al. 2011). Studies in lung cancer cells have demonstrated that hypoxia induces EMT through protein kinase A (PKA) activity in a hypoxiainducible factor 1-alpha (HIF1- $\alpha$ ) dependent manner (Shaikh et al. 2012). A variety of druggable targets have been identified as potential mechanisms to control EMT induction and/or target the mesenchymal phenotype which is a consequence of EMT (Davis et al. 2014b). One class of proteins that are the target of existing drugs and many drug development programs are ion channels. Plasmalemmal ion channels in particular are often amenable to pharmacological modulation due to their extracellular domains. The availability of selective inhibitors to specific ion channel isoforms also allows chemogenomic and other methods to develop new therapeutics.

\section{Ion channels as regulators of cellular processes}

The presence of ion gradients across the plasma membrane is a defining feature of mammalian cells. The sodium ion gradient is maintained by $\mathrm{Na}^{+} / \mathrm{K}^{+}$-ATPases that actively pump $\mathrm{Na}^{+}$ions from the cytoplasm to maintain a lower intracellular free $\mathrm{Na}^{+}$level compared to those of the extracellular space (Castillo et al. 2015). Changes in this gradient can lead to rapid changes in membrane potential and drive action potentials in excitable cells. Similarly, changes in cytosolic free $\mathrm{Ca}^{2+}\left(\left[\mathrm{Ca}^{2+}\right]_{\mathrm{CYT}}\right)$ levels can be mediated by activation of $\mathrm{Ca}^{2+}$ permeable ion channels and such changes have important roles in an array of cellular processes including fertilization, muscle contraction, hormone secretion, gene transcription and cell death (Berridge et al. 2003). The diversity of processes influenced by changes in $\mathrm{Na}^{+}, \mathrm{Ca}^{2+}$ and $\mathrm{K}^{+}$and other ions through the opening of ion channels, requires the 
cell to selectively control such changes and the way such changes are decoded to alter cellular processes. Hence, it is not surprising that there are a plethora of ion channels in cells. For example there are over 20 genes that encode for just one specific class of ion channel - transient receptor potential (TRP) channels in humans. The next section provides an outline of the general properties of ion channels relevant to this review. We then provide a specific overview of studies that have identified roles of ion channels in EMT induction and/or remodelling.

\section{Plasma membrane ion channels}

There are a variety of ion channels with different permeability and selectivity for cations or anions. A comprehensive review of all ion channels even just those of the plasma membrane is well beyond the scope of this review. Hence, readers are directed to sources of comprehensive lists and review of ion channels such as the IUPHAR/BPS guide to pharmacology (Southan et al. 2016), which includes other channels not discussed in this review such as acid-sensing (proton-gated) ion channels (ASICs) and some ligand gated $\mathrm{Ca}^{2+}$ channels such as ionotropic glutamate receptors. Arguably, the most extensively studied plasma membrane ion channels are those depicted in Fig. 2 - which include calcium channels, sodium channels, potassium channels and chloride channels. Examination of each of these channel types provides insight into their diversity. These channels can differ dramatically in their properties from ion selectivity to their mechanism of activation.

The diversity in ion channel properties is clear in the plasma membrane $\mathrm{Ca}^{2+}$ channels presented in Fig. 2 Orai, TRP, P2X and voltage gated $\mathrm{Ca}^{2+}$ channels (VGCC). These classes have clear differences in their mechanism of activation. For example the Orai1 protein is part of a complex whereby $\mathrm{Ca}^{2+}$ influx is activated by the depletion of endoplasmic reticulum $\mathrm{Ca}^{2+}$ stores (Azimi et al. 2014). In contrast, TRP channels have been described as sensors, as exemplified by TRPV1 a $\mathrm{Ca}^{2+}$ permeable ion channel activated by heat and the hot chilli component, capsaicin (Azimi et al. 2014). Other ligand gated calcium channels include ionotropic glutamate receptors and also P2X channels that are activated by some nucleosides (e.g. ATP) whereas VGCCs are activated by changes in membrane potential (Azimi et al. 2014). Even within classes of $\mathrm{Ca}^{2+}$ channels there is great diversity of activators (e.g. TRPV1 is activated by capsaicin whereas TRPM8 is activated by menthol) and ion selectivity (e.g. TRPV6 is highly selective for $\mathrm{Ca}^{2+}$ ions whereas TRPV1 is also permeable to $\mathrm{Na}^{+}$ions) (Azimi et al. 2014). The remodelling of $\mathrm{Ca}^{2+}$ channel expression has been defined in some cancers and some have been identified as potential therapeutic targets in some cancer subtypes as reviewed elsewhere

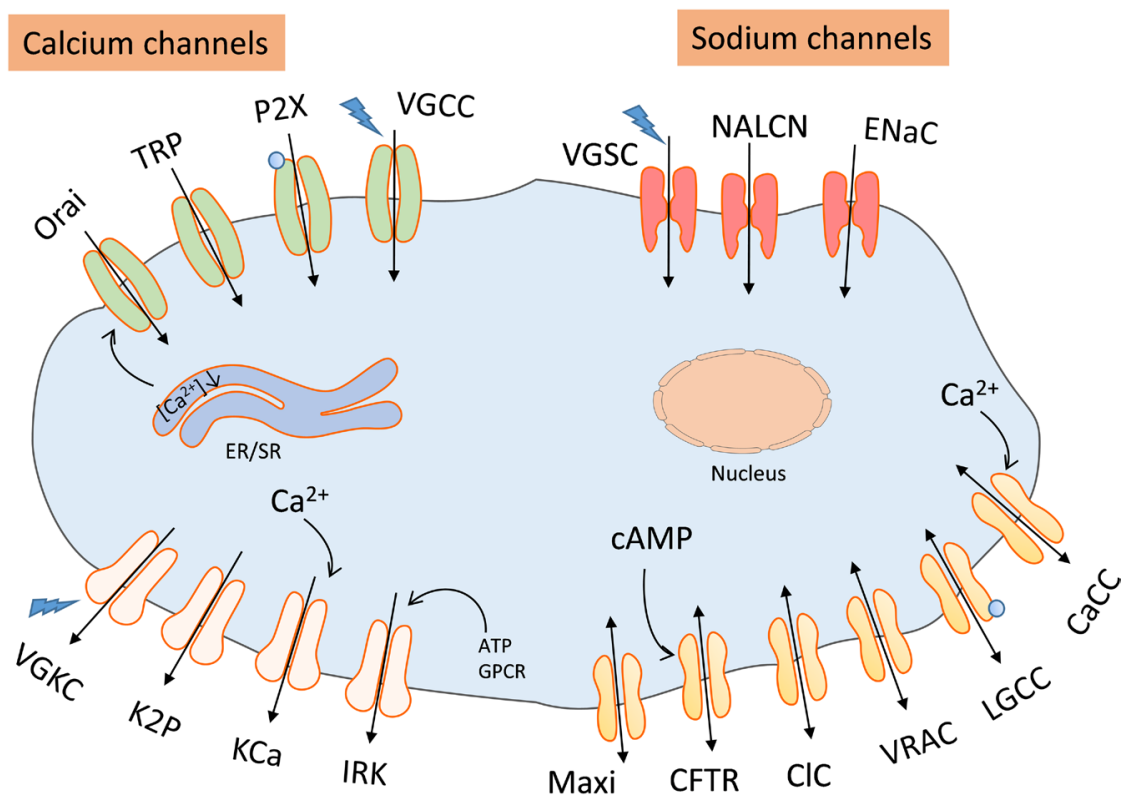

Potassium channels

\section{Figure 2}

Plasma membrane ion channels. Plasma membrane calcium channels include Orai (activated by $\mathrm{Ca}^{2+}$ store depletion), transient receptor potential (TRP), P2X (activated by ligands such as ATP), and voltage gated $\mathrm{Ca}^{2+}$ channels (VGCC). Plasma membrane sodium channels include voltage-gated sodium channels (VGSC), sodium leak channel (NALCN) and epithelial sodium channel (ENaC). Plasma membrane potassium channels include voltage gated channels (VGKC two-pore domain (K2P) channels, $\mathrm{Ca}^{2+-a c t i v a t e d ~ c h a n n e l s ~(K C a) ~ a n d ~}$ inwardly rectifying channels (IRK). Plasma membrane chloride channels include maxi channels, cystic fibrosis transmembrane conductance regulator (CFTR), $\mathrm{Ca}^{2+-a c t i v a t e d}$ channels ( $\mathrm{CaCC})$, ligand-gated channels (LGCC), volume-regulated anion channels (VRAC), and the chloride channel superfamily (CIC). 
(Azimi et al. 2014, Stewart et al. 2015). Indeed, SOR-C13, a TRPV6 inhibitor has been recently assessed in clinical trials of ovarian cancer (www.clinicaltrials.gov, NCT01578564).

Although the association between $\mathrm{Na}^{+}$influx and action potentials has seen a focus on $\mathrm{Na}^{+}$channel in neuroscience and cardiovascular research, $\mathrm{Na}^{+}$channels are in fact expressed in a variety of cell types. For example voltage gated sodium channels (VGSC) are expressed in excitable cells including neurons and muscle cells, where they are responsible for action potential and conduction (Southan et al. 2016); NALCN has been described as a sodium leak channel which regulates the resting membrane potential and excitability in neurons (CochetBissuel et al. 2014); and epithelial sodium channels $(\mathrm{ENaC})$ play pivotal roles in the regulation of extracellular fluid (ECF) volume and blood pressure in kidney tubules (Hanukoglu \& Hanukoglu 2016). Potassium channels are equally as complex and diverse and include those that are voltage gated (VGKC), those that are two-pore domain $(\mathrm{K} 2 \mathrm{P})$, those that play roles in $\mathrm{Ca}^{2+}$-activated $\mathrm{K}^{+}$transport (KCa channels) and Inwardly rectifying $\mathrm{K}^{+}$(IRK) channels (Hibino et al. 2010).

Chloride channels include channels that when defective due to hereditary mutation can alter the fluid transport in epithelial cells resulting in cystic fibrosis (Cystic Fibrosis Transmembrane conductance Regulator (CFTR)), channels activated by intracellular $\mathrm{Ca}^{2+}(\mathrm{CaCC})$, those which are ligand activated (LGCC), or volume regulated (VRAC) or the chloride channel superfamily (CIC) (Southan et al. 2016).

The outline of plasmalemmal ion channels presented above highlighted the diversity of ion channels and their roles in mammalian cells. As discussed below, some of these ion channels have recently been shown to be remodelled as a consequence of EMT in cancer cells or play roles in the induction of EMT markers induced by some stimuli.

\section{Plasma membrane ion channels and EMT in cancer cells}

This review is focused on the remodelling and in some cases roles of ion channels in EMT in cancer cells. It should be noted that other studies have investigated ion channels in EMT in the context of other EMT relevant processes many of which intersect with disease states such as airway remodelling (Arthur et al. 2015) and renal fibrosis (Mai et al. 2016).

The very different properties of cancer cells such as the acquisition of therapeutic resistance and the major changes in the expression of specific proteins (e.g. vimentin) and transcription factors (e.g. twist and Snail) as a consequence of EMT means that changes in ion influx should not have been surprising. The change in phenotype of cancer cells that have undergone EMT and the very specific roles of specific ion channels in different cell types suggests that the mesenchymal phenotype will exploit different ion channels to achieve different cellular functions. In the section below we will provide an overview of studies that have now shown such changes and in some cases implicated specific ion channels in EMT induction. Many of these studies are summarised in Table 1.

\section{Sodium channels and EMT in cancer cells}

Hypotheses have been proposed and an intellectual case made for the potential of voltage-gated sodium channels to regulate EMT induction in cancer cells (Eren \& Oyan 2014, Eren et al. 2015). The repositioning of clinically used voltage-gated sodium channel blockers to attenuate metastatic progression and/or chemotherapy resistance through inhibition of EMT induction has also been highlighted (Eren et al. 2015). However, this area has yet to be fully assessed experimentally with models of EMT in cancer cells, and this represents an opportunity for future research.

\section{Potassium channels and EMT in cancer cells}

The association between changes in the potassium gradient and EMT was suggested in early studies of potassium chloride co-transporter 3 (KCC3) (Hsu et al. 2007). KCC3 is not an ion channel, but its ability to cotransport $\mathrm{K}^{+}$ and $\mathrm{Cl}^{-}$ions makes it an important regulator of the flux of these ions across the plasma membranes of many cell types where it can play an important role in the regulation of cell volume (Hsu et al. 2007, Kahle et al. 2015). Forced overexpression of KCC3 in cervical cancer SiHa cells is associated with the adoption of a more mesenchymal-like morphology, the down regulation of the epithelial marker E-cadherin and the upregulation of the mesenchymal marker vimentin (Hsu et al. 2007). Subsequent to these studies an association with the EAG1 potassium channel and EMT in lung cancer cells has been implicated, because of an increase in Eag1 mRNA levels in A549 lung cancer cells treated with transforming growth factor beta 1 (TGF $\beta 1$ ), an EMT inducer in this model (Restrepo-Angulo et al. 2011). In context of colorectal cancer, studies of phosphatase of regenerating liver-3 (PRL-3) induced EMT in LoVo cells

Published by Bioscientifica Ltd 
Table 1 Ion channels with roles in EMT in cancer cells. List of ion channels that have been identified to be remodelled during EMT and/or have roles in the induction of EMT in cancer cells, including the target they affect and any characterised consequential effects.

\begin{tabular}{|c|c|c|c|}
\hline Channel & EMT induced by & Cancer & Cell line \\
\hline TRPM7 & EGF & Breast & MDA-MB-468 \\
\hline Orai1/STIM1 & Oct4 silencing & Breast & MCF7 \\
\hline TRPM8 & $\begin{array}{l}\text { Basal } \\
\text { (not induced) }\end{array}$ & Breast & MDA-MB-231 \\
\hline TRPC6 & Doxorubicin & $\begin{array}{l}\text { Hepatocellular } \\
\text { carcinoma }\end{array}$ & Huh7 and HepG2 \\
\hline KCNN4 & PRL-3 & Colorectal & LoVo \\
\hline EAG1 & TGF $\beta 1$ & Lung & A549 \\
\hline CLCA2 & $\begin{array}{l}\text { Basal } \\
\text { (not induced) }\end{array}$ & Breast & HMLE \\
\hline CLCA4 & TGF $\beta$ & Breast & HMLE \\
\hline CFTR & TGF- $\beta 1$ & Breast & MCF7MDA-MB-231 \\
\hline TMEM16A & $\begin{array}{l}\text { Basal } \\
\text { (not induced) }\end{array}$ & Head and neck & $\mathrm{T} 24$ \\
\hline
\end{tabular}

\begin{tabular}{l} 
Mechanism/affected target \\
\hline Vimentin protein-possibly via \\
STAT3 \\
E-cadherin and $\alpha$-smooth \\
muscle actin ( $\alpha$-SMA)-possible \\
mechanism via enhancement \\
in SOCE
\end{tabular}

Activating AKT/glycogen

synthase kinase-3 beta (GSK-3 $\beta$ )

E-cadherin-regulation of calcium-dependant multidrug resistance (MDR)

Snail and E-cadherin. Mechanism via CaM-kinase II GSK-3 $\beta$

TGF $\beta 1$-induced EMT upregulates EAG1 mRNA and protein expression-consequence was not explained

Loss of CLCA2 promotes EMT, migration and invasion

Via upregulating N-cadherin, Yu et al. (2013) vimentin, and fibronectin, and downregulating E-cadherin

Downregulation of CFTR promotes EMT, migration and invasion

Silencing promotes EMT by regulation of snail and E-cadherin

\section{Reference \\ Davis et al. (2014a)}

Hu et al. (2011)

Liu et al. (2014)

Wen et al. (2016)

Lai et al. (2013)

Restrepo-Angulo et al. (2011)

Walia et al. (2012)

Zhang et al. (2013a)

Shiwarski et al. (2014) (a colon cancer cell line), has shown that a pharmacological inhibitor of the $\mathrm{Ca}^{2+}$ activated potassium channel KCNN4 - TRAM-34, supresses the mesenchymal markers vimentin and Snail, and increases the expression of the epithelial marker E-cadherin (Lai et al. 2013). Although the concentrations of TRAM-34 used may have inhibited other ion channels, siRNA to KCNN4 phenocopied the effects of TRAM-34 (Lai et al. 2013). Moreover, KCNN4 expression was positively correlated with tumour stage in clinical cohort of 86 patient colorectal tumour samples (Lai et al. 2013). Very recent studies have now shown that silencing of KCNN4 in MDA-MB-231 (a breast cancer cell line with features of the mesenchymal phenotype) appeared to reduce the expression of the mesenchymal markers vimentin and Snail (Zhang et al. 2016).

Collectively, the studies described above are beginning to define associations between specific potassium channels and EMT in cancer cells. Further studies of other potassium channels in the context of changes in expression as a consequence of EMT as well as the induction of EMT and/or maintenance of the mesenchymal phenotype now seem appropriate. Given the diversity of EMT models in cancer cells and the variety of inducers of EMT, it is also important that the roles of specific potassium channels be investigated across a variety of models and inducers of EMT.

\section{Chloride channels and EMT in cancer cells}

An increasing number of studies have identified the remodelling of expression of chloride channel components as a consequence of EMT in cancer cells. Examples of such remodelling include isoforms of chloride channel accessory proteins, namely CLCA2 and CLCA4. CLCA2 mRNA levels are reduced in breast cancer cell lines associated with the mesenchymal phenotype (e.g. MDA-MB-231 and BT549) compared to those often enriched in epithelial markers (e.g. MCF-7). Indeed, expression of the EMT

Published by Bioscientifica Ltd 
transcription factor Snail supresses CLCA2 protein in the human breast cell line MCF10A, and CLCA2 levels are reduced in subpopulations of cells from the human mammary epithelial (HMLE) cell line that are enriched in mesenchymal markers (Walia et al. 2012). Moreover, CLCA2 levels are reduced during EMT induced by TGF $\beta$ (Yu et al. 2013). Similarly, reduced levels of the related isoform CLCA4 is a feature of subpopulations of cells from the HMLE cell line that are enriched in mesenchymal markers and a consequence of TGF $\beta$-induced EMT (Yu et al. 2013). Consistent with the loss of CLCA2 and CLCA4 in the mesenchymal phenotype, low levels of CLCA2 and CLCA4 appear likely to be associated with an increased incidence of metastasis (as assessed through metastasis or relapse free survival) using specific cohorts of breast cancer patients (Walia et al. 2012, Yu et al. 2013). In addition to their remodelling as a consequence of EMT, CLCA2 and CLCA4 have also been implicated in the regulation of the transition of breast cancer cells towards a more mesenchymal state. Knockdown of CLCA2 or CLCA4 is sufficient in HMLE cells to induce the expression of the mesenchymal marker vimentin and supress the epithelial marker E-Cadherin (Walia et al. 2012, Yu et al. 2013). In the case of CLCA2, the regulation of EMT may at least in part be through interactions with the cell junctional protein EVA1 (Ramena et al. 2016). Future studies are now required to define the relative importance in changes in chloride flux in these events, and the ability of the loss of CLCA2 or CLCA4 to induce a mesenchymal phenotype in other models of EMT, including those not of breast cancer origin.

Breast cancer cells have also been the focus of investigators exploring the relationship between CFTR and EMT. The EMT inducer TGF $\beta 1$ causes a down regulation of CFTR in MCF-7 cells, which is also associated with a down regulation of the epithelial marker E-cadherin (Zhang et al. 2013a). A functional role for CFTR in EMT induction is suggested by the ability of CFTR silencing to induce the expression of a variety of mesenchymal markers in MCF-7 breast cancer cells. This proposed function of CFTR is further supported by the ability of CFTR overexpression in mesenchymal-like MDA-MB-231 breast cancer cells to suppress the expression of vimentin (a mesenchymal marker) and induce the expression of E-cadherin (an epithelial marker) (Zhang et al. 2013a). As would be predicted based on these results, reduced levels of CFTR are associated with poor prognosis in breast cancer patients (Zhang et al. 2013a). More recent studies have begun to explore chloride channels in the context of EMT in other cancer types, such as squamous cell carcinomas of the head and neck (Shiwarski et al. 2014). TMEM16A (also known as ANO1), is one of a reported subset (termed Anoctamins) of calcium activated chloride channels (Kunzelmann et al. 2011). Levels of TMEM16A are reduced in cancer cells in metastatic lymph nodes compared to those of the primary tumour in squamous cell carcinomas of the head and neck (Shiwarski et al. 2014). TMEM16A seems to be more than a potential marker of EMT, since silencing of TMEM16A in T24 cells (a human bladder carcinoma cell line), produces a mesenchymallike phenotype (spindle morphology, lower E-cadherin, increased Snail) and overexpression of TMEM16A produces an epithelial-like phenotype (rounded packed morphology, increased E-cadherin, reduced vimentin and fibronectin) (Shiwarski et al. 2014).

The work described above, performed by a variety of investigators using an array of models and approaches has now helped define a remodelling of specific chloride channels (or components) in EMT and a role for these same channels in the induction of EMT and/or the maintenance of the epithelial-like phenotype.

\section{Calcium channels and EMT in cancer cells}

The calcium signal has been identified as or could be speculated to be a potential mechanism by which at least some of the aforementioned ion channels may immediate their effects on EMT. For example the mechanism by which KCNN4 may regulate EMT in colon cancer cells has been linked to effects on calcium signalling (Lai et al. 2013). Indeed, global chelation of intracellular free $\mathrm{Ca}^{2+}$ that attenuates increases in cytosolic free $\mathrm{Ca}^{2+}$, suppresses both EGF and hypoxia induced increases in the mesenchymal markers vimentin, $\mathrm{N}$-cadherin and CD44 (Davis et al. 2014a). Similar findings have now been reported in Huh7 and HepG2 hepatic cancer cell lines for EMT induced by doxorubicin (Wen et al. 2016). It is also now clear that a major remodelling in calcium signalling and the expression of specific calcium permeable ion channels is a feature of EMT and some calcium permeable ion channels are important in the induction of expression of some proteins associated with the mesenchymal phenotype.

Alterations in the responses to ATP, able to activate G-protein coupled purinergic receptors (P2Y family) and ligand gated $\mathrm{Ca}^{2+}$ channels (P2X family) is a feature of both EGF and hypoxia induced EMT in MDA-MB-468 breast cancer cells (Davis et al. 2011, Azimi et al. 2015). 
EMT induced by hypoxia and EGF is associated with the attenuation of peak $\left[\mathrm{Ca}^{2+}\right]_{\mathrm{CYT}}$ and the sustained phase of $\mathrm{Ca}^{2+}$ influx induced by ATP. EMT is also associated with a reduction in the sensitivity to ATP with an increase the $\mathrm{EC}_{50}$ (Davis et al. 2011, Azimi et al. 2015). Such changes in the mesenchymal phenotype may be an adaption of breast cancer cells to the high ATP concentrations in some tumour microenvironments. However, despite this consistent change in ATP-mediated $\mathrm{Ca}^{2+}$ signalling, the nature of the remodelling of $\mathrm{P} 2 \mathrm{X}$ receptors seems very different as the upregulation of P2X5 mRNA is a feature of EGF but not hypoxia associated ATP (Davis et al. 2011, Azimi et al. 2015). The attenuation of store operated $\mathrm{Ca}^{2+}$ entry (SOCE) and basal $\mathrm{Ca}^{2+}$ influx is also a feature of EGF induced EMT in MDA-MB-468 (Davis et al. 2012), however, assessment of such changes with hypoxia induced EMT has not been reported. Such studies are critical given that in MCF-7 cells, the EMT inducer TGF- $\beta 1$ has been reported to be associated with enhancement of store operated $\mathrm{Ca}^{2+}$ entry (Hu et al. 2011).

In addition to a remodelling of $\mathrm{Ca}^{2+}$ influx and/or the expression of some $\mathrm{Ca}^{2+}$ permeable ion channels in EMT in cancer cells, specific calcium permeable ion channels have also been identified as regulators of the induction of at least some hallmarks of EMT. A focused siRNA screen identified TRPM7 as a regulator of EGF-induced expression of the mesenchymal marker vimentin in MDA-MB-468 breast cancer cells (Davis et al. 2014a). A pharmacological inhibitor of TRPM7 replicated the consequences of TRPM7 silencing on EGF induced vimentin expression. These effects were not due to general inhibition of EGF receptor (EGFR) signalling since EGF-mediated EGFR and AKT phosphorylation were unaffected by TRPM7 silencing, however, EGF-mediated STAT3 and ERK1/2 phosphorylation were significantly reduced (Davis et al. 2014a). Although a $\mathrm{Ca}^{2+}$ permeable ion channel, the importance of TRPM7 in $\mathrm{Mg}^{2+}$ homeostasis and its ability to function as an atypical alpha kinase (Paravicini et al. 2012) require further attention into the nature of its contribution to EMT in some cancer models. Silencing of the cold sensor TRPM8 increases the expression of the epithelial marker E-cadherin in mesenchymal-like MDA-MB-231 cells and reduces levels of the mesenchymal marker vimentin (Liu et al. 2014). Consistent with a role for TRPM8 in the maintenance and/or induction of the mesenchymal phenotype in breast cancer cells, overexpression of TRPM8 in the more epithelial like MCF-7 cell line leads to EMT induction as indicated by down regulation of E-cadherin and induction of vimentin (Liu et al. 2014). In Huh7 and HepG2 hepatic cancer cells,
TRPC6 silencing attenuates changes in the expression of E-cadherin induced by doxorubicin suggesting that in the ability of TRPC6 silencing to increase sensitivity to doxorubicin through effects of resistance pathways may be due at least in part to effects on some aspects of EMT induction (Wen et al. 2016).

Hence, studies of calcium signalling and $\mathrm{Ca}^{2+}$ permeable ion channels in EMT from a variety of groups using an array of EMT inducers and models have helped define a critical role for the $\mathrm{Ca}^{2+}$ signal in EMT in cancer cells.

\section{Conclusion}

An increasing number of studies have reported the remodelling of plasma membrane ion channel expression as a characterizing feature of EMT in cancer cells. The identification of the role of specific ion channels in the induction of EMT and/or the maintenance of aspects of the epithelial or mesenchymal-like phenotype in cancer cells suggest that some ion channels may be therapeutic targets to control EMT and hence disease progression (e.g. therapeutic resistance). However, it is likely that different EMT inducers may engage different ion channels to regulate the properties of the mesenchymal phenotype and/or EMT induction itself. This issue and the study of the intersection between sex hormones and receptors that regulate EMT (Zuo et al. 2010, van der Horst et al. 2012, Sun et al. 2014, Kong et al. 2015, Jeon et al. 2016) and ion channels which themselves intersect with sex hormone pathways (Asuthkar et al. 2015, Hao et al. 2015, Mahmoodzadeh et al. 2016) are areas for future research. Which ion channels to pursue for therapeutic targeting requires careful consideration, and deciding factors will include the expression of targets in other cell types and the likely adverse systemic effects of channel inhibitors. However, the successful use of ion channel inhibitors for conditions as diverse as cardiovascular disease to pain demonstrated the need to continue research in this area.

Declaration of interest

GRM is associated with QUE-Oncology Inc. The authors declare that there is no conflict of interest that could be perceived as prejudicing the impartiality of this review.

\section{Funding}

The research was supported by the National Health and Medical Research Council (NHMRC; project grant 1079672). G R M was supported by the Mater Foundation. The Translational Research Institute is supported by a grant from the Australian Government.

Published by Bioscientifica Ltd 


\section{References}

Arthur GK, Duffy SM, Roach KM, Hirst RA, Shikotra A, Gaillard EA \& Bradding P $2015 \mathrm{~K}(\mathrm{Ca}) 3.1 \mathrm{~K}+$ channel expression and function in human bronchial epithelial cells. PLoS ONE 10 e0145259. (doi:10.1371/journal.pone.0145259)

Asuthkar S, Elustondo PA, Demirkhanyan L, Sun X, Baskaran P, Velpula KK, Thyagarajan B, Pavlov EV \& Zakharian E 2015 The TRPM8 protein is a testosterone receptor I. Biochermical evidence for direct TRPM8-testoesterone intersactions. Journal of Biological Chemistry 290 2659-2669. (doi:10.1074/jbc.M114.610824)

Azimi I, Beilby H, Davis FM, Marcial DL, Kenny PA, Thompson EW, Roberts-Thomson SJ \& Monteith GR 2015 Altered purinergic receptor-Ca signaling associated with hypoxia-induced epithelialmesenchymal transition in breast cancer cells. Molecular Oncology 10 166-178. (doi:10.1016/j.molonc.2015.09.006)

Azimi I, Roberts-Thomson SJ \& Monteith GR 2014 Calcium influx pathways in breast cancer: opportunities for pharmacological intervention. British Journal of Pharmacology 171 945-960. (doi:10.1111/bph.12486)

Berridge MJ, Bootman MD \& Roderick HL 2003 Calcium signalling: dynamics, homeostasis and remodelling. Nature Reviews: Molecular Cell Biology 4 517-529. (doi:10.1038/nrm1155)

Bokobza SM, Ye L, Kynaston H \& Jiang WG 2011 Growth and differentiation factor 9 (GDF-9) induces epithelial-mesenchymal transition in prostate cancer cells. Molecular and Cellular Biochemistry 349 33-40. (doi:10.1007/s11010-010-0657-5)

Castillo JP, Rui H, Basilio D, Das A, Roux B, Latorre R, Bezanilla F \& Holmgren M 2015 Mechanism of potassium ion uptake by the $\mathrm{Na}+/ \mathrm{K}+-$ ATPase. Nature Communications 6 7622. (doi:10.1038/ ncomms8622)

Cochet-Bissuel M, Lory P \& Monteil A 2014 The sodium leak channel, NALCN, in health and disease. Frontiers in Cellular Neuroscience $\mathbf{8}$ 132. (doi: 10.3389/fncel.2014.00132)

Davis FM, Kenny PA, Soo ET, van Denderen BJ, Thompson EW, Cabot PJ, Parat MO, Roberts-Thomson SJ \& Monteith GR 2011 Remodeling of purinergic receptor-mediated $\mathrm{Ca}^{2+}$ signaling as a consequence of EGFinduced epithelial-mesenchymal transition in breast cancer cells. PLOS ONE 6 e23464. (doi:10.1371/journal.pone.0023464)

Davis FM, Peters AA, Grice DM, Cabot PJ, Parat MO, RobertsThomson SJ \& Monteith GR 2012 Non-stimulated, agoniststimulated and store-operated Ca2+ influx in MDA-MB-468 breast cancer cells and the effect of EGF-induced EMT on calcium entry. PLOS ONE 7 e36923. (doi:10.1371/journal.pone.0036923)

Davis FM, Azimi I, Faville RA, Peters AA, Jalink K, Putney JW Jr, Goodhill GJ, Thompson EW, Roberts-Thomson SJ \& Monteith GR $2014 a$ Induction of epithelial-mesenchymal transition (EMT) in breast cancer cells is calcium signal dependent. Oncogene $\mathbf{3 3}$ 2307-2316. (doi:10.1038/onc.2013.187)

Davis FM, Stewart TA, Thompson EW \& Monteith GR 2014b Targeting EMT in cancer: opportunities for pharmacological intervention. Trends in Pharmacological Sciences 35 479-488. (doi:10.1016/j. tips.2014.06.006)

Eren OO \& Oyan B 2014 Voltage-gated sodium channel blockade for inhibition of EMT. Trends in Pharmacological Sciences 35 621-621. (doi:10.1016/j.tips.2014.10.003)

Eren OO, Ozturk MA, Sonmez OU \& Oyan B 2015 Voltage-gated sodium channel blockers can augment the efficacy of chemotherapeutics by their inhibitory effect on epithelial-mesenchymal transition. Medical Hypotheses 84 11-13. (doi:10.1016/j.mehy.2014.11.006)

Fischer KR, Durrans A, Lee S, Sheng JT, Li FH, Wong STC, Choi HJ, El Rayes T, Ryu SH, Troeger J, et al. 2015 Epithelial-to-mesenchymal transition is not required for lung metastasis but contributes to chemoresistance. Nature $\mathbf{5 2 7}$ 472-476. (doi:10.1038/nature15748)

Hanahan D \& Weinberg RA 2011 Hallmarks of cancer: the next generation. Cell 144 646-674. (doi:10.1016/j.cell.2011.02.013)
Hanukoglu I \& Hanukoglu A 2016 Epithelial sodium channel (ENaC) family: phylogeny, structure-function, tissue distribution, and associated inherited diseases. Gene 579 95-132. (doi:10.1016/j. gene.2015.12.061)

Hao J, Bao X, Jin B, Wang X, Mao Z, Li X, Wei L, Shen D \& Wang JL $2015 \mathrm{Ca} 2+$ channel subunit alpha 1D promotes proliferation and migration of endometrial cancer cells mediated by 17beta-estradiol via the G protein-coupled estrogen receptor. FASEB Journal 29 2883-2893. (doi:10.1096/fj.14-265603)

Heerboth S, Housman G, Leary M, Longacre M, Byler S, Lapinska K, Willbanks A \& Sarkar S 2015 EMT and tumor metastasis. Clinical and Translational Medicine 4 6. (doi:10.1186/s40169-015-0048-3)

Hibino H, Inanobe A, Furutani K, Murakami S, Findlay I \& Kurachi Y 2010 Inwardly rectifying potassium channels: their structure, function, and physiological roles. Physiological Reviews 90 291-366. (doi:10.1152/physrev.00021.2009)

Hsu YM, Chen YF, Chou CY, Tang MJ, Chen JH, Wilkins RJ, Ellory JC \& Shen MR 2007 KCI cotransporter-3 down-regulates E-cadherin/betacatenin complex to promote epithelial-mesenchymal transition. Cancer Research 67 11064-11073. (doi:10.1158/0008-5472.CAN-07-2443)

Hu JJ, Qin KH, Zhang Y, Gong JB, Li N, Lv D, Xiang R \& Tan XY 2011 Downregulation of transcription factor Oct4 induces an epithelial-tomesenchymal transition via enhancement of $\mathrm{Ca} 2+$ influx in breast cancer cells. Biochemical and Biophysical Research Communications 411 786-791. (doi:10.1016/j.bbrc.2011.07.025)

Jeon SY, Hwang KA \& Choi KC 2016 Effect of steroid hormones, estrogen and progesterone, on epithelial mesenchymal transition in ovarian cancer development. Journal of Steroid Biochemistry and Molecular Biology 158 1-8. (doi:10.1016/j.jsbmb.2016.02.005)

Kahle KT, Khanna AR, Alper SL, Adragna NC, Lauf PK, Sun DD \& Delpire E $2015 \mathrm{~K}-\mathrm{Cl}$ cotransporters, cell volume homeostasis, and neurological disease. Trends in Molecular Medicine 21 513-523. (doi:10.1016/j.molmed.2015.05.008)

Kalluri R \& Weinberg RA 2009 The basics of epithelial-mesenchymal transition. Journal of Clinical Investigation 119 1420-1428. (doi:10.1172/JCI39104)

Kong DJ, Sethi S, Li YW, Chen W, Sakr WA, Heath E \& Sarkar FH 2015 Androgen receptor splice variants contribute to prostate cancer aggressiveness through induction of emt and expression of stem cell marker genes. Prostate 75 161-174. (doi:10.1002/pros.22901)

Kunzelmann K, Tian YM, Martins JR, Faria D, Kongsuphol P, Ousingsawat J, Thevenod F, Roussa E, Rock J \& Schreiber R 2011 Anoctamins. Pflugers Archiv-European Journal of Physiology $\mathbf{4 6 2}$ 195-208. (doi:10.1007/s00424-011-0975-9)

Lai W, Liu L, Zeng YJ, Wu H, Xu HY, Chen S \& Chu ZH 2013 KCNN4 channels participate in the EMT induced by PRL-3 in colorectal cancer. Medical Oncology 30 566. (doi:10.1007/s12032-013-0566-z)

Lamouille S, Xu J \& Derynck R 2014 Molecular mechanisms of epithelial-mesenchymal transition. Nature Reviews: Molecular Cell Biology 15 178-196. (doi:10.1038/nrm3758)

Lester RD, Jo M, Montel V, Takimoto S \& Gonias SL 2007 uPAR induces epithelial-mesenchymal transition in hypoxic breast cancer cells. Journal of Cell Biology 178 425-436. (doi:10.1083/jcb.200701092)

Liu JX, Chen YZ, Shuai S, Ding DP, Li R \& Luo RC 2014 TRPM8 promotes aggressiveness of breast cancer cells by regulating EMT via activating AKT/GSK-3 beta pathway. Tumor Biology 35 8969-8977. (doi:10.1007/s13277-014-2077-8)

Mahmoodzadeh S, Haase H, Sporbert A, Rharass T, Panakova D \& Morano I 2016 Nuclear translocation of the cardiac L-type calcium channel C-terminus is regulated by sex and 17beta-estradiol. Journal of Molecular and Cellular Cardiology 97 226-234. (doi:10.1016/j. yjmcc.2016.06.004)

Mai X, Shang J, Liang S, Yu B, Yuan J, Lin Y, Luo R, Zhang F, Liu Y, Lv X, et al. 2016 Blockade of Orai1 store-operated calcium entry protects against renal fibrosis. Journal of the American Society of Nephrology [in press]. (doi:10.1016/j.yjmcc.2016.06.004) 
Paravicini TM, Chubanov V \& Gudermann T 2012 TRPM7: a unique channel involved in magnesium homeostasis. International Journal of Biochemistry and Cell Biology 44 1381-1384. (doi:10.1016/j. biocel.2012.05.010)

Ramena G, Yin YF, Yu Y, Walla V \& Elble RC 2016 CLCA2 interactor EVA1 is required for mammary epithelial cell differentiation. PLoS ONE 11 e0147489. (doi:10.1371/journal.pone.0147489)

Restrepo-Angulo I, Sanchez-Torres C \& Camacho J 2011 Human EAG1 potassium channels in the epithelial-to-mesenchymal transition in lung cancer cells. Anticancer Research 31 1265-1270.

Shaikh D, Zhou QY, Chen TJ, Ibe JCF, Raj JU \& Zhou GF 2012 cAMPdependent protein kinase is essential for hypoxia-mediated epithelialmesenchymal transition, migration, and invasion in lung cancer cells. Cellular Signalling 24 2396-2406. (doi:10.1016/j.cellsig.2012.08.007)

Shiwarski DJ, Shao CB, Bill A, Kim J, Xiao D, Bertrand CA, Seethala RS, Sano D, Myers JN, Ha P, et al. 2014 To 'Grow' or 'Go': TMEM16A expression as a switch between tumor growth and metastasis in SCCHN. Clinical Cancer Research 20 4673-4688. (doi:10.1158/10780432.CCR-14-0363)

Singh A \& Settleman J 2010 EMT, cancer stem cells and drug resistance: an emerging axis of evil in the war on cancer. Oncogene 29 4741-4751. (doi:10.1038/onc.2010.215)

Southan C, Sharman JL, Benson HE, Faccenda E, Pawson AJ, Alexander SPH, Buneman OP, Davenport AP, McGrath JC, Peters JA, et al. 2016 The IUPHAR/BPS Guide to PHARMACOLOGY in 2016: towards curated quantitative interactions between 1300 protein targets and 6000 ligands. Nucleic Acids Research 44 D1054-D1068. (doi:10.1093/nar/gkv1037)

Stewart TA, Yapa KTDS \& Monteith GR 2015 Altered calcium signaling in cancer cells. Biochimica et Biophysica Acta-Biomembranes 1848 2502-2511. (doi:10.1016/j.bbamem.2014.08.016)

Sun Y, Wang YS, Fan C, Gao P, Wang XW, Wei GW \& Wei JM 2014 Estrogen promotes stemness and invasiveness of ER-positive breast cancer cells through Gli1 activation. Molecular Cancer 13137. (doi:10.1186/1476-4598-13-137)

Thiery JP, Acloque H, Huang RYJ \& Nieto MA 2009 Epithelialmesenchymal transitions in development and disease. Cell 139 871-890. (doi:10.1016/j.cell.2009.11.007)

Tsai JH \& Yang J 2013 Epithelial-mesenchymal plasticity in carcinoma metastasis. Genes and Development 27 2192-2206. (doi:10.1101/ gad.225334.113)

van Denderen BJW \& Thompson EW 2013 Cancer the to and fro of tumour spread. Nature 493 487-488. (doi:10.1038/493487a) van der Horst PH, Wang YY, Vandenput I, Kuhne LC, Ewing PC, van IJcken WFJ, van der Zee M, Amant F, Burger CW \& Blok LJ 2012 Progesterone inhibits epithelial-to-mesenchymal transition in endometrial cancer. PLOS ONE 7 e30840. (doi:10.1371/journal. pone.0030840)

Walia V, Yu Y, Cao D, Sun M, McLean JR, Hollier BG, Cheng J, Mani SA, Rao K, Premkumar L, et al. 2012 Loss of breast epithelial marker hCLCA2 promotes epithelial-to-mesenchymal transition and indicates higher risk of metastasis. Oncogene 31 2237-2246. (doi:10.1038/onc.2011.392)

Wen L, Liang C, Chen EJ, Chen W, Liang F, Zhi X, Wei T, Xue F, Li GG, Yang $Q$, et al. 2016 Regulation of multi-drug resistance in hepatocellular carcinoma cells is TRPC6/calcium dependent. Scientific Reports 6 23269. (doi:10.1038/srep23269)

Yu Y, Walia V \& Elble RC 2013 Loss of CLCA4 promotes epithelial-tomesenchymal transition in breast cancer cells. PLOS ONE 8. (doi:10.1371/journal.pone.0083943)

Zhang JT, Jiang XH, Xie C, Cheng H, Dong JD, Wang Y, Fok KL, Zhang XH, Sun TT, Tsang LL, et al. 2013a Downregulation of CFTR promotes epithelial-to-mesenchymal transition and is associated with poor prognosis of breast cancer. Biochimica et Biophysica ActaMolecular Cell Research 1833 2961-2969. (doi:10.1016/j. bbamcr.2013.07.021)

Zhang SM, Wang X, Iqbal S, Wang YR, Osunkoya AO, Chen ZJ, Chen Z, Shin DM, Yuan HW, Wang YQA, et al. 2013b Epidermal growth factor promotes protein degradation of epithelial protein lost in neoplasm (EPLIN), a putative metastasis suppressor, during epithelial-mesenchymal transition. Journal of Biological Chemistry $\mathbf{2 8 8}$ 1469-1479. (doi:10.1074/jbc.M112.438341)

Zhang PS, Yang XW, Yin Q, Yi JL, Shen WZ, Zhao L, Zhu Z \& Liu JW 2016 Inhibition of SK4 potassium channels suppresses cell proliferation, migration and the epithelial-mesenchymal transition in triple-negative breast cancer cells. PLOS ONE 11 e0154471. (doi:10.1371/journal.pone.0154471)

Zheng XF, Carstens JL, Kim J, Scheible M, Kaye J, Sugimoto H, Wu CC, LeBleu VS \& Kalluri R 2015 Epithelial-to-mesenchymal transition is dispensable for metastasis but induces chemoresistance in pancreatic cancer. Nature 527 525-530. (doi:10.1038/nature16064)

Zuo LA, Li W \& You SJ 2010 Progesterone reverses the mesenchymal phenotypes of basal phenotype breast cancer cells via a membrane progesterone receptor mediated pathway. Breast Cancer Research 12 R34. (doi:10.1186/bcr2588)

Received in final form 5 September 2016

Accepted 12 September 2016

Accepted Preprint published online 12 September 2016
(C) 2016 Society for Endocrinology Printed in Great Britain
Published by Bioscientifica Ltd 